\title{
UM MOMENTO IMPORTANTE NA FORMAÇÃO DOS \\ LICENCIANDOS DO PIBID: A TRANSIÇÃO DE ALUNO A \\ PROFESSOR E A CONSTITUIÇÃO DE SUA IDENTIDADE PROFISSIONAL
}

\author{
Rafael Conde Barbosa \\ Pontifícia Universidade Católica de \\ São Paulo \\ Selma Alfonsi \\ Pontifícia Universidade Católica de \\ São Paulo \\ Sylvia Bachiegga \\ Pontifícia Universidade Católica de \\ São Paulo
Marli Elisa Dalmazo Afonso de André São Paulo \\ Pontifícia Universidade Católica de
}

\section{Resumo}

Este estudo visa identificar como discentes participantes do PIBID percebem seu processo de formação, bem como quais concepções e intenções revelam em relação à docência. Foram realizados três grupos de discussão em cidades de São Paulo, Rio Janeiro e Minas Gerais. As pesquisas de Marcelo e Vaillant (2011), Placco e Souza (2006) contribuíram para as análises, que indicaram três eixos: influência na escolha da docência; reflexão sobre a prática do outro - pertença negada com base nas atribuições que são reconhecidas à docência e a passagem de aluna à professora. Como resultados destacam-se: a influência de alguns professores formadores, na permanência dos discentes no curso de licenciatura e que os cursos de formação inicial devem privilegiar a troca e ressignificação das experiências vivenciadas pelos alunos, em outros espaços de formação.

Palavras-chave: Formação inicial; Inserção na docência; PIBID. 


\title{
AN IMPORTANT MOMENT IN THE EDUCATIONAL PROCESS OF GRADUATE STUDENTS WHO TAKE PART IN PIBID: THE TRANSITION FROM BEING A STUDENT TO BEING A TEACHER AND THE CONSTITUTION OF THEIR PROFESSIONAL IDENTITY
}

\begin{abstract}
This study aims to identify how the graduate students, who take part in PIBID, realize their own educational process and which conceptions and intentions they reveal in relation to teaching practice. Three discussion groups were carried out in cities in the states of São Paulo, Rio de Janeiro and Minas Gerais. The studies of Marcelo and Vaillant (2011), Placco and Souza (2006) have given a great contribution to the analysis that indicated three main aspects: influence over students' professional choices; reflection upon the practice of other partners - denied belonging based on the attributions that are made to teaching and the transition from being a student to being a teacher. The results show: the influence some teacher educators have over their graduate students decision to continue attending their courses and also that the graduation courses should privilege the trade of experience students have had in other educational centers.
\end{abstract}

Keywords: Teacher's Education; Teaching; PIBID. 


\section{Introdução}

A profissão docente, assim como qualquer outra, tem especificidades e características próprias, principalmente quando se refere aos primeiros anos do exercício docente.

Com o objetivo de compreender como algumas alunas de cursos de licenciatura fazem a transição da discência para a docência, procuramos identificar como esses sujeitos percebem suas condições de participantes do Programa Institucional de Bolsa de Iniciação à Docência (PIBID), bem como quais concepções e intenções revelam em relação à docência.

O PIBID é uma iniciativa do Governo Federal, que busca a articulação entre a formação inicial docente e a prática profissional, desenvolvida nas escolas públicas. Nesse programa, os docentes do ensino superior desenvolvem projetos disciplinares específicos, que serão integrados pelos licenciandos em parceria com a escola e com o docente titular da sala de aula. Os projetos são pensados e elaborados a partir da análise da demanda dos professores da escola pública.

Dentre os objetivos principais do PIBID figuram a articulação teoria prática na formação inicial; valorização do magistério; inserção dos licenciandos no dia-a-dia da sala de aula; e modificação da prática do estágio, convidando o professor a se perceber como coformador do futuro docente (BRASIL, 2013).

Considerando as questões que envolvem a formação inicial, o ingresso na docência e o processo de constituição identitária dos licenciandos, encontramos nas pesquisas de Marcelo (2009), Marcelo e Vaillant (2011), Vaillant (2012), Placco (2008), Placco e Souza (2006) subsídios para embasar este estudo.

A tarefa de pensar os processos formativos torna-se um tanto complexa quando se perde de vista as necessidades do presente, que precisam ser identificadas, o que nem sempre acontece. Esse momento demanda o olhar de um bom professor.

Olh@res, Guarulhos, v. 2, n. 1, p. 302-319. Maio, 2014. 
Um momento importante na formação dos licenciandos do PIBID: a transição de aluno a professor e a constituição de sua identidade profissional

Adotando como eixo a formação inicial dos professores, Marcelo e Vaillant (2011), e Vaillant (2012) procuram pistas e tentam indicar quais seriam as características de um bom professor, as quais elencamos a seguir. Segundo esses autores, uma boa formação inicial, pensada para as escolas de amanhã e da atualidade deve:

- incutir no futuro docente o compromisso com a aprendizagem do seu aluno;

- propiciar uma bagagem de conhecimentos que permitam a ele ter domínio do conteúdo e habilidade para ensiná-los;

- mostrar ao graduando a importância da gestão da aprendizagem de seus alunos;

- permitir que ele possa pensar sistematicamente a sua prática, bem como aprender com a sua experiência;

- estimular o envolvimento do futuro docente em comunidades de aprendizagens;

- estimular os graduandos a serem provocadores de questionamentos, em seus alunos, induzindo-os ao desenvolvimento de um pensamento reflexivo;

- mostrar aos futuros docentes que, além de domínio dos conteúdos, eles precisam ser entusiasmados com a sua ação;

- e ensinar-lhes a ter uma postura flexível frente às diferentes formas de lidar com os conteúdos e seus alunos nos diversos contextos.

Sabemos que são muitas as características necessárias ao futuro docente, no entanto, gostaríamos de chamar a atenção para um aspecto que consideramos de suma importância, qual seja, seu papel na aprendizagem dos alunos. $\mathrm{Na}$ sociedade em que vivemos o docente precisa estar ciente de que, diferentemente de algumas décadas atrás, a escola hoje não é o local principal, nem o único, onde os alunos encontram informação. Faz-se necessário que o futuro docente esteja preparado para dar mais do que respostas a problemas técnicos, que, como nos lembram os autores, são aqueles que têm o conhecimento disponível pode resolver. Frente à dinamicidade

Olh@res, Guarulhos, v. 2, n. 1, p. 302-319. Maio, 2014. 
da nossa sociedade, bem como por ser a escola, ainda, um espaço privilegiado, ocupado por profissionais, que devem auxiliar seus alunos na tarefa de interpretar a realidade, é preciso ser capaz de filtrar as informações e tentar encontrar, em meio às situaçõ es de incerteza e de imprevisibilidade, proposições e alternativas que ajudem a enfrentar os problemas do presente.

Como buscamos, nesta pesquisa, entender o processo de transição de aluno a professor, a questão de como ocorrem os movimentos identitários de discentes de diferentes cursos de licenciatura é também nosso foco de interesse. Recorremos aos -estudos de Dubar (2005, 2012), teórico da sociologia, que nos ajuda a compreender como o sujeito negocia suas expectativas, necessidades e desejos, com aquilo que lhe é atribuído e/ou imposto pelo contexto de trabalho.

Pelo fato de as participantes desta pesquisa ainda estarem em processo de formação e sua prática docente ser desenvolvida na execução dos projetos realizados entre a universidade e a escola pública, a experiência que possuem ainda é a de discentes. Como afirma Marcelo (2009), o professor aprende sua profissão mesmo antes de atuar, pois passa pela experiência da observação do que é ser professor ainda enquanto aluno, desde a educação básica:

\begin{abstract}
A identidade docente vai, assim, se configurando de forma paulatina e pouco reflexiva por meio do que poderíamos denominar aprendizagem informal, mediante a qual os futuros docentes vão recebendo modelos com os quais vão se identificando pouco a pouco, e em cuja construção influem mais os aspectos emocionais do que os racionais. (MARCELO, 2009, p.116)
\end{abstract}

Considerando o fato de o docente ser o profissional que possui mais tempo imerso na profissão e de que os cursos de graduação nem sempre oferecem aos seus alunos uma formação consistente, na e para a prática, faz-se necessário identificar quais são os aspectos que influenciam a constituição identitária do professor, antes de se graduar, ao sair de uma licenciatura e ao iniciar sua atuação numa instituição escolar.

Olh@res, Guarulhos, v. 2, n. 1, p. 302-319. Maio, 2014. 
Um momento importante na formação dos licenciandos do PIBID: a transição de aluno a professor e a constituição de sua identidade profissional

Os conhecimentos adquiridos durante a graduação muitas vezes são dispensados quando o professor "entra em cena" com seus alunos. Ao conhecer a rotina da sala de aula e as reações de seus alunos, ele opta por incorporar certos conhecimentos práticos, adquiridos enquanto aluno, observando seus professores, descartando ou dando pouco valor aos conhecimentos teóricos adquiridos na graduação, que na realidade, dão embasamento e suporte à sua ação em sala de aula.

A sincronia entre teoria e prática nem sempre é entendida, especialmente para os sujeitos que ainda estão em processo de formação profissional. No entanto, conhecimentos teóricos e práticos estão em contínua inter-relação. Os saberes da prática precisam ser reinterpretados à luz de uma teoria e é nesse processo reflexivo que o sujeito negociará as suas crenças, valores, aspectos subjetivos, que foram formados por meio das suas próprias experiências, com as crenças, valores e aspectos subjetivos da instituição onde está inserido. A este processo, Dubar (2005) nomeia transação subjetiva (indivíduo) e transação objetiva (outros) ${ }^{1}$.

Mesmo reconhecendo que Dubar (2005) não estuda a inserção profissional docente, procuramos transpor alguns pontos de sua teoria para o processo de formação dos professores. Entendemos que é na atividade profissional e na interação com seus pares que o professor se identifica ou não com os diversos papéis que vivencia. Estas diferentes situações permitem que ele aceite ou não a imagem, as funções, as intenções sobre o que é ser professor, existente no ambiente ao qual pertence e em que está integrado.

\footnotetext{
${ }^{1}$ Para Dubar, estas transações "podem assumir duas formas: ou de transações "externas" entre o indivíduo e os outros significativos, visando a tentar acomodar a identidade para si à identidade para o outro (transação denominada objetiva), ou a de transações "internas" ao indivíduo entre a necessidade de salvaguardar uma parte de suas identificações anteriores (identidades herdadas) e o desejo de construir para si novas identidades no futuro (identidades visadas), com vistas a tentar assimilar a identidade-parao-outro à identidade-para-si. Essa transação, denominada subjetiva, constitui um processo de socialização concebido como produtor de identidades sociais" (2005, p.140).
}

Olh@res, Guarulhos, v. 2, n. 1, p. 302-319. Maio, 2014. 
Negociar interna e externamente essas crenças, concepções, valores, imagens e desejos do "ser professor" implica um movimento que sofre influências, não só da instituição a qual pertence, mas também de toda a sociedade que, por vezes, não contribui para que o professor legitime sua profissionalidade Para as autoras Placco e Souza, a deliberação envolvida no processo de constituição docente implica consciência, "no sentido de estar consciente do que se busca e dos movimentos que se está empreendendo na direção desses objetivos” (2006, p. 19).

Ter consciência dos movimentos ocorridos em seu processo de constituição identitária auxiliará o professor na legitimação de sua profissão e de sua valorização profissional. Para atingir essa consciência, necessita mobilizar recursos internos (subjetivos) e externos (objetivos) que se desenvolvem continuamente ao longo de sua trajetória profissional e pessoal. Assim, buscamos dar voz ao professor, para que ele ressignifique suas experiências no momento em que se narra e se ouve, promovendo a articulação entre transação objetiva e subjetiva, representando "a projeção do espaço-tempo identitário de uma geração confrontada com as outras" (DUBAR, 2005, p.156).

\section{Metodologia}

Os dados foram coletados por pesquisadoras que atuam nas instituições em que as discentes fazem os cursos de licenciatura. Procedemos às análises dos dados, buscando indicadores que pudessem revelar como o PIBID contribui para a formação e a constituição identitária docente. Foram realizados três grupos de discussão com alunas participantes do PIBID de três instituições: uma localizada no interior de SP, com 11 discentes, uma na capital do Rio de Janeiro, com 10 discentes e outra no interior de Minas Gerais, com 6 discentes.

Olh@res, Guarulhos, v. 2, n. 1, p. 302-319. Maio, 2014. 
Um momento importante na formação dos licenciandos do PIBID: a transição de aluno a professor e a constituição de sua identidade profissional

A escolha dessa metodologia foi motivada pela possibilidade de viabilizar a livre elaboração e o desenvolvimento de uma discussão sobre um determinado tema. Com isso, buscávamos obter dados que expressassem o que pensam e sentem as alunas participantes do PIBID a respeito de seu desenvolvimento pessoal e profissional.

Considerando que os processos de constituição identitária não são dados a priori e que a identidade permeia o modo dos sujeitos serem e estarem no mundo (GATTI, 1996; MARCELO, 2009), fez-se necessário conhecer os contextos nos quais esses professores constituem suas identidades, ou seja, entender como eles negociam as atribuições que lhes são conferidas por pais, alunos, mídia, pelos gestores e por seus pares, e o que, de fato, eles acreditam ser sua responsabilidade.

\section{O que caracteriza um grupo de discussão?}

Nossa concepção de grupo de discussão está baseada em Weller e Pfaff (2011). Segundo essas pesquisadoras, ao utilizar essa técnica, o pesquisador atua como um moderador do grupo, intervindo o mínimo possível, pois deve ser um facilitador da discussão e interferirá na fala do grupo somente quando for chamado ou quando precisar reconduzir os participantes à discussão do tema de interesse proposto pelo pesquisador. Desse modo, será o grupo quem conduzirá a discussão.

Tendo em vista a intencionalidade do pesquisador em fazer com que o grupo discuta determinado assunto de seu interesse, este estará atento ao modo como as falas dos diferentes participantes interferem ou exercem influência umas nas outras. Nesses grupos, é comum que os participantes tenham uma certa vivência sobre o assunto a ser discutido e, no caso desta pesquisa, o critério de seleção foi o de que as discentes participassem do PIBID.

Apesar da atuação do pesquisador como mediador e da sua não interferência nas falas, este deve ter clareza do que espera que surjam durante as discussões. De acordo com Weller e Pfaff (2011), o que se

Olh@res, Guarulhos, v. 2, n. 1, p. 302-319. Maio, 2014. 
busca conhecer não são os porquês, mas as opiniões das participantes. 0 mediador orienta o grupo no sentido de que o sujeito descreva, narre a sua ação e as suas experiências. Esse processo narrativo tem como intenção fazer com que os participantes reflitam sobre o que estão dizendo e, dessa forma, possam ressignificar sua ação ou mudar interpretações que possam ter sobre determinado assunto.

Essa narrativa é importante para o pesquisador, pois será a partir dela que ele, com a ajuda de seu referencial teórico, interpretará as falas e conhecerá o contexto em que são produzidas. Vale a pena relembrar que esse discurso é fruto da sua experiência e da interação com o grupo, e que os participantes têm em comum o fato de compartilharem vivências semelhantes.

Pode-se questionar o fato de que o pesquisador irá trabalhar com as falas dos sujeitos individualmente, porém, como explica Weller e Pfaff (2011), nos grupos de discussão, a opinião do grupo não é a soma das opiniões dos participantes, mas sim o produto das interações desses sujeitos. Portanto, não se deve perder de vista que o pesquisador, ao analisar as falas, considerará a influência que existe entre as falas dos entrevistados. O que busca é conhecer como são construídas as visões de mundo do grupo e não dos sujeitos individualmente.

O moderador precisa dispor de um roteiro no qual possa acompanhar se os assuntos que deseja conhecer estão surgindo nas falas e trocas entre os participantes. Um cuidado que o pesquisador deve ter é não dirigir as perguntas, que eventualmente venha a fazer, a nenhum dos sujeitos em particular. Os possíveis questionamentos devem ser sempre dirigidos para o grupo.

Como forma de criar um ambiente mais descontraído, visando tirar a tensão que normalmente pesa sobre a figura do pesquisador e sobre o gravador que utilizará, o pesquisador iniciará a discussão com uma pergunta ou situação de aquecimento, que mobilize todos os participantes a se sentirem à vontade no grupo. O ideal é que todos

Olh@res, Guarulhos, v. 2, n. 1, p. 302-319. Maio, 2014. 
Um momento importante na formação dos licenciandos do PIBID: a transição de aluno a professor e a constituição de sua identidade profissional

falem e espera-se que o pesquisador tenha deixado claro para os sujeitos a importância da participação de todos, bem como, que não há certo ou errado; o que se deseja é conhecer a opinião e as representações coletivas dos participantes, sobre determinado assunto.

\section{Análise dos dados}

Durante as leituras das transcrições das falas dos grupos de discussão, tivemos como foco a busca por elementos que revelassem qual ou quais seriam as concepções que as alunas, futuras docentes, possuem sobre a docência e em que aspectos o programa interfere ou não na sua constituição identitária. A análise das falas, produzidas nesses três grupos, nos indicaram três eixos: a) influência na escolha da docência; b) reflexão sobre a prática do outro - pertença negada com base nas atribuições que são reconhecidas à docência; e c) a passagem de aluna à professora - (re)construção da docência para si.

Estudar os movimentos identitários é tarefa árdua e por mais que se elaborem categorias para proceder às análises das falas dos sujeitos, optamos, neste texto, por fazer uma escrita contínua. A tarefa a que nos propomos é produzir um texto no qual as falas se mesclem e revelem ao leitor a dinamicidade das transformações que se operam na transição da posição de aluno à de docente.

Escolher uma profissão não é tarefa das mais simples, tendo-se em vista as grandes transformações, tecnológicas ou sociais, que verificamos na atualidade. Quando voltamos nosso olhar para a escola e consideramos as mudanças aí ocorridas percebemos algo contraditório, causando-nos perplexidade. Estamos diante de uma profissão que vem perdendo prestígio, ao longo do tempo, e que não consegue, hoje em dia, atrair bons alunos para os cursos de licenciatura e tampouco mantê-los, depois de formados, nas salas de aula.

Olh@res, Guarulhos, v. 2, n. 1, p. 302-319. Maio, 2014. 
Como indicam Marcelo e Vaillant (2011) na atualidade, especificamente na América Latina, verifica-se que ingressam nas licenciaturas aqueles alunos que tiveram uma formação básica deficitária e fragmentada, o que não contribui para que se tenha docentes mais bem formados nos cursos de formação inicial e nem para que estes se sintam capazes de lidar e se ver, com segurança, diante das situações com as quais serão confrontados na sala de aula. É comum encontrarmos falas que indiquem a resistência dos familiares quando se anuncia a escolha pela carreira docente. Motivos como violência, baixos salários, desprestígio social são as primeiras coisas que ouvimos quando perguntamos sobre o que pensam sobre essa profissão. Nas falas das estudantes participantes desta pesquisa, esses argumentos aparecem, porém, mesmo diante dessas adversidades, elas optaram pela docência.

Importante destacar a influência dos professores da educação básica na transformação das concepções que os futuros professores possuem sobre o estudo e especificamente sobre o papel do professor na escolha da carreira. Uma das alunas do grupo do RJ afirma que: “estava encarando tanto a negatividade da profissão de ser professor, que quando [...] (se) deparou com a escola ela viu que não é essa negação toda, [...] (a escola) é um lugar de possibilidades."

Sendo a escola um lugar de possibilidades, encontramos no grupo das alunas de São Paulo, pistas, que podem ser consideradas positivas pelos docentes formadores de futuros professores, para que estes repensem suas ações, considerando que, seu modo de agir, bem como o conteúdo que ensinam, podem não produzir resultados naquele momento específico, mas que a sua dedicação e preparo, que estão além daquilo que está prescrito oficialmente nos documentos, poderá reverberar positivamente nas escolhas que seus alunos farão no futuro. Como uma das integrantes do grupo de SP indica:

$\mathrm{O}$ que me motivou a entrar na licenciatura foi porque, na quinta série, eu entrei na sala de aula e eu sempre detestei história, [...] eu odiava mesmo. Eu ficava de recuperação final em todas... todos os anos da minha vida eu ficava em história. Era impressionante. Aí eu

Olh@res, Guarulhos, v. 2, n. 1, p. 302-319. Maio, 2014. 
cheguei na quinta série e entrou um professor novo na escola. Ele tinha acabado de sair da faculdade e chegou imitando os homens primitivos dentro da sala de aula, fazendo um teatro. Aquilo lá não era aula de história, aquilo lá era um teatro. Entendeu? E, a partir daí eu só tirava dez em história, e, assim eu comecei a amar. Eu falei "quero ser professora de história". (Grupo - SP)

Não estamos propondo que todos os professores devam agir como se estivessem em um palco, porém o que nos chama a atenção nesse relato é o olhar que este professor, recém saído da faculdade, teve para com seus alunos. Como afirmam Marcelo e Vaillant (2011) é importante que o professor consiga criar um clima que motive os estudantes a quererem aprender. E pensando no clima da aula, para ensinar um conteúdo, ele se valeu de uma linguagem artística para atingir seu público.

Defendemos, também, que o professor deve dialogar, tanto com seus pares, como com seus alunos. Ainda no grupo de São Paulo, observamos que outras participantes tiveram experiência semelhante. Umas das integrantes afirma:

Foi um professor que me incentivou a querer ser professora. Então olha a influência que um professor tem na vida de um aluno. A gente não está mexendo com produto, a gente está mexendo com vida. Por isso que eu acho que tem que ter muito amor naquilo que a gente faz entendeu. É por isso que eu digo que se um dia eu não gostar mais de estar na sala de aula eu pego as minhas coisas e vou embora. Porque se eu estou lá é porque eu gosto, é porque eu quero. (Grupo - SP)

Um aspecto que não pode ser negligenciado pelo professor formador é que as suas ações precisam ser planejadas e que ele precisa ter consciência dos fins que pretende atingir. É necessário que tenha clareza de onde partirá com seus alunos e onde pretende chegar com eles (PLACCO, 2008).

Como pode ser observado acima, a ação do professor está sendo interpretada pelos seus alunos e estes, no momento em que se depararem com a necessidade de mobilizar saberes para atuar na sua sala de aula, conscientemente ou não, recorrerão a modelos que eles apreciavam ou até muitas vezes desprezavam, mas no calor do momento, acabam repetindo as mesmas ações de seus professores. Não pretendemos depreciar essas atitudes, mas sim chamar a atenção

Olh@res, Guarulhos, v. 2, n. 1, p. 302-319. Maio, 2014. 
para que, mesmo que utilizem modelos que considerem corretos, é importante que consigam filtrar, daqueles momentos vividos, aquilo que é pertinente ser aplicado ao contexto em que se encontram.

Resgatando um dos motivos que orientou esta pesquisa, que é verificar como se constitui a identidade profissional das alunas participantes do PIBID, podemos afirmar que o projeto, ao inserir as alunas na escola, tem contribuído de forma positiva para que essas futuras professoras (re)interpretem as situações que viveram na educação básica, enquanto alunas, bem como as que vivenciam, na faculdade e na escola, como participantes dos projetos desenvolvidos nas escolas públicas.

A inserção destas alunas em contextos reais de trabalho permite que elas deixem de ser meras expectadoras e passem a ser protagonistas da sua própria formação. Elas participam da execução dos projetos elaborados na parceria entre a faculdade e a escola pública e isto possibilita que, ao mesmo tempo em que aprendem a teoria na faculdade, possam aplicá-la na escola. Faz-se necessário esclarecer que as graduandas não são as professoras da sala, mas atuam como professoras no desenvolvimento das atividades com os alunos nos projetos.

Pensando na constituição identitária dessas futuras professoras e na sua inserção na escola, Dubar (2012) esclarece que a entrada no mercado de trabalho possibilita que o sujeito experimente e verifique até que ponto os conhecimentos que ele acumulou são úteis e que "a vida de trabalho é feita, ao mesmo tempo, de relações com parceiros [...] inseridas em situações de trabalho, marcados por imprevistos, continuidades e rupturas, êxitos e fracassos" (p.358).

As falas das alunas do grupo de Minas Gerais revelam esse movimento. Ao mesmo tempo em que tecem críticas ao trabalho de outras docentes, elas propõem ações que julgam mais pertinentes:

Olh@res, Guarulhos, v. 2, n. 1, p. 302-319. Maio, 2014. 
não estou criticando o projeto, nem a escola, nem a professora, pois ela deve saber o que está fazendo, mas a gente vê muitas coisas negativas. [...] Nós temos um olhar muito crítico para dentro daquele espaço. Nós mesmas achamos muito angustiante o que estamos vivenciando. Sabemos que quando formos professoras podemos ter problemas, não exercer uma prática interessante, motivadora para o aluno, que não vamos ser uma professora cem por cento, mas a experiência nos faz enxergar muitas coisas que não queremos fazer quando formos professoras. (Grupo - MG)

Mais do que analisar o comportamento das colegas, essas alunas estão tendo a oportunidade de refletir sobre a importância de se autoavaliarem, buscando um aperfeiçoamento que promova, tanto o seu próprio crescimento profissional, como o de seus alunos. Nesse movimento, elas reconhecem que também são passíveis de erro e isso, de certa forma, possibilita que elas cresçam criticamente no papel de professoras e passem a se distanciar do papel de alunas. Como indicam as participantes do grupo de São Paulo e de Minas Gerais, quando apontam uma das contribuições do PIBID:

eu acho que quando a gente está dentro da sala de aula no papel de professor a gente aprende a valorizar mais os nossos professores. Porque a gente começa a ver o quanto é difícil você passar um dia todo preparando uma aula, chegar para aplicar e o aluno não prestar a mínima atenção em você. [...] Quando você inverte os papéis é que você percebe o quanto é importante respeitar para ser respeitado, o quanto é importante cooperar. Nem toda aula é interessante, nem todo assunto é legal. Mas sabe, é só o respeito pelo professor já conta porque é muito chato você estar lá na frente e o aluno não te respeitar. (Grupo - SP)

uma das aprendizagens que tive foi compreender a importância de fazer reflexão e ter sensibilidade para perceber o que se passa, porque igual ao que a colega está falando, você acaba refletindo sobre aquela prática do professor, seja boa ou não, porque você tá ali observando e às vezes ele nem percebe, muita coisa que o professor faz é tão natural que ele nem percebe. (Grupo MG)

Além da influência dos professores da educação básica, as alunas atribuem um papel positivo, tanto à figura de alguns professores do ensino superior, quanto à figura das coordenadoras do PIBID, quando citam a razão da permanência no curso. É válido ressaltar que essa opinião não é unânime, como afirma o grupo de Minas Gerais:

Acho que não podemos deixar de destacar o papel da nossa coordenadora [...], porque assim... a gente vê que alguns subprojetos aí que os coordenadores estão, mas não gostam muito daquela área, já a (nossa coordenadora) não, (ela) é uma pessoa apaixonada nessa área Educação Infantil, que se dedica o tempo todo e faz com todo prazer, então isso influencia muito pra gente, dá vontade de conhecer a Educação Infantil como

Olh@res, Guarulhos, v. 2, n. 1, p. 302-319. Maio, 2014. 
ela conhece, de ser uma professora que entende, acho que ela tem grande influência na minha escolha.

O docente formador e o coordenador são modelos para seus alunos professores e como Marcelo e Vaillant (2011) indicam, o estilo de trabalho, não prescrito oficialmente, revela o compromisso, o grau de comprometimento e a responsabilidade desses profissionais com sua profissão e com seus alunos, e seu desejo de que seus alunos professores, de alguma forma, internalizem este fazer, sem esquecer ainda o domínio do conteúdo a ser ensinado.

O conhecimento do conteúdo, a clareza dos objetivos traçados e quais os caminhos que poderá percorrer com seus alunos, é possível àqueles que, estando à frente da sala de aula, têm clareza, consciência e intencionalidade no seu agir. As alunas participantes do PIBID revelam que o perfil de professor descompromissado e que não sabe como agir não é o que elas têm como modelo. Ao negarem essas condutas, elas demonstram que há outros caminhos que podem ser percorridos e que a teoria pode fornecer pistas nessa trajetória de ressignificações constantes. O grupo de São Paulo deixa claro a influência e o papel que um professor (des)comprometido pode ter na formação de seus alunos:

Mas sabe por que eles são bons no nosso convívio escolar? Porque a gente consegue perceber muitos professores que a gente quer ser igual, mas nesses casos a gente consegue perceber os professores que a gente não quer ser. A gente consegue daí ter uma base de "eu vou me espelhar em fulano, mas eu jamais quero ser como ciclano." (Grupo SP)

Não podemos esquecer que um bom professor não é alguém que possui apenas amplo domínio do conteúdo que ensina. Como bem indicaram as alunas, os professores continuam tendo influência sobre a permanência ou não na profissão, porém os professores formadores devem ter ouvidos e olhos atentos para se reavaliarem e conseguirem reinterpretar suas ações, para poderem conhecer que tipo de docentes eles estão formando, pois, afinal de contas, precisamos de alunos que consigam cruzar a ponte da discência para a docência com mais

Olh@res, Guarulhos, v. 2, n. 1, p. 302-319. Maio, 2014. 
Um momento importante na formação dos licenciandos do PIBID: a transição de aluno a professor e a constituição de sua identidade profissional

segurança e que sejam capazes de usar a teoria em um cenário em constante transformação.

\section{Considerações finais}

O processo de aprendizagem desse adulto, futuro professor, como os caminhos que o levam a constituir a sua identidade não são imutáveis nem estáticos. Tanto a ação como a identidade docente constituem-se nas diversas situações do cotidiano e nas negociações que esse docente tem que fazer com seus alunos, com a equipe gestora da escola onde leciona e com seus pares que, em tese, deveriam ser parceiros na elaboração, construção e ressignificação de conhecimentos que possibilitem o desenvolvimento dos seus alunos e que permitam, ao docente, tornar-se mais consciente dos instrumentos e mecanismos que ele mobiliza para fazer o outro - bem como ele mesmo - aprender.

Aliado ao fato de que os professores formadores continuam a exercer influência positiva ou não na decisão dos alunos de permanecerem na profissão, vimos que o PIBID, ao possibilitar a essas alunas uma atuação prática nas escolas, permite a elas, também, observarem e expressarem a importância da teoria para a execução de uma boa prática docente. Esse fato leva-nos a observar que elas não parecem inclinadas a adotar práticas comodistas ou até mesmo medíocres, na condução de suas aulas. Isso fica evidenciado nesta pesquisa, no momento em que elas refletem sobre a própria prática e buscam outros caminhos para alcançar os objetivos propostos nos projetos.

A guisa de conclusão, defendemos a ideia de que os cursos de formação inicial ou continuada precisam contar com formadores conscientes da importância do seu papel e de como a sua ação interfere no futuro comportamento que o seu aluno, graduando, adotará no futuro quando estiver à frente de uma sala de aula, vivenciando situações reais, com alunos reais e com problemas imprevisíveis.

Olh@res, Guarulhos, v. 2, n. 1, p. 302-319. Maio, 2014. 
Retomando uma fala de Placco (2008, p.189) “se o trabalho do formador implica desenvolvimento profissional e formação de professores, deve incluir o estudo e a crítica das teorias". Este movimento intencional por parte do formador, provocará mudanças que podem ser conduzidas conscientemente, em diferentes espaços de formação, seja no espaço da sala de aula da universidade, com a discussão de diferentes teorias, ou a sala de aula da Educação Básica com o desenvolvimento de projetos que possibilitem ao aluno reinterpretar suas ações e questionar as teorias.

Olh@res, Guarulhos, v. 2, n. 1, p. 302-319. Maio, 2014. 
Um momento importante na formação dos licenciandos do PIBID: a transição de aluno a professor e a constituição de sua identidade profissional

Referências

BRASIL, MEC. PIBID - Programa Institucional de bolsa de Iniciação à Docência. Brasília, 2013. Disponível em: http://www.capes.gov.br/educacao-basica/capespibid. Acesso em: Abril. 2013.

DUBAR, Claude. A socialização: construção das identidades sociais e profissionais. São Paulo, Ed. Martins Fontes, 2005. XXVII, 343p.

Claude. A construção de si pela atividade de trabalho: a socialização

profissional. Cadernos de Pesquisa, São Paulo, v.42, n.146, p.351-367, maio/ago. 2012.

GATTI, Bernardete. Os professores e suas identidades: o desvelamento da heterogeneidade. Cadernos de Pesquisa, São Paulo, n.98, p.85-90, ago. 1996.

MARCELO, Carlos. A identidade docente: constantes e desafios. Revista Formação Docente, Belo horizonte, v. 01, n.01, p.109-131, ago./dez. 2009.

Carlos; VAILlanT, Denise. Desarollo Professional Docente: Cómo se aprende a enseñar?. Madrid, Ed. Narcea, 2011. 171p.

PLACCO, Vera M.N. de S., SOUZA, Vera L. T. Aprendizagem do Adulto Professor. São Paulo, Ed. Loyola, 2006. 95p.

Vera M.N. de S. Processos Multidimensionais na Formação de Professores. p. 185-198. In. Desafios da Formação de Professores para o Século XXI: O que deve ser ensinado? O que deve ser aprendido?. Ed. Universidade Federal do Sergipe, 2008.

VAILLANT, Denise. Formación inicial del profesor para las escuelas del mañana. Revista Diálogo Educacional, Curitiba,v.12, n.35, p.167-186, jan./abr. 2012.

WELlER, Wivian; PFAFF, Nicolle. Metodologias de Pesquisa da Pesquisa Qualitativa em Educação: teoria e prática. 2a ed., Petrópolis, RJ: vozes, 2011. 336p.

Olh@res, Guarulhos, v. 2, n. 1, p. 302-319. Maio, 2014. 